\title{
EFFECT OF ORGANIZATIONAL SKILLS AND COMPETENCIES ON PERCEIVED JOB PERFORMANCE WITH MEDIATION OF MULTITASKING
}

\author{
Kumail Raza Hemani ${ }^{1}$ \\ Assistant Professor, Management Science Department, SZABIST Karachi \\ Dr. Zaki Rashidi ${ }^{2}$ \\ Professor Management Science SZABIST Karachi
}

\begin{abstract}
In today's modern and complex organizations, multitasking has become an increasingly occurred phenomenon and is considered as one of the key determinants in performance appraisals. With the advent of the technological advances, changing organizational structures and shrinking timelines, multitasking is being viewed as an important requirement. In modern work environments, to do more than one task at a time and have deliverables overlapping on one another requires an employee to multi task and juggle between two tasks at one time. The argument leads to the question that does attainment of several tasks overlapping has an impact on the effectiveness of the task and whether multitasking is something and employee will comfortable with to achieve better perceived performance or not. Perceived job performance and successful completion of work has been viewed as an employee's ability to multitask whereas there have been research studies which have argued the negative social implication of employees multitasking. Technology, timelines, characteristics and attributes required for certain positions and designations keep multitasking as one of the key element while also giving the core competencies and skills required for multitasking.
\end{abstract}

Keywords: Organizational Skills and Competency, Multitasking, Job Performance

\footnotetext{
* The material presented by the author does not necessarily portray the viewpoint of the editors and the management of the Institute of Business \& Technology (IBT)

1 Kumail Raza Hemani

2 Dr. Zaki Rashidi

(C) IBT-JBS is published by the Institute of Business and Technology (IBT).

Main Ibrahim Hydri Road, Korangi Creek, Karachi-75190, Pakistan.
} 


\section{INTRODUCTION}

Competence can be defined as an ability or willingness of an individual to perform a task; it can further seen as area of work whereas a competency can be looked at as the behavior of the employees supporting the area of work and finally as the attributes underpinning a behavior .Organizational skills have been defined in previous researches as the behavioral skills or Non-Cognitive Skills that an employee must possess; competencies are the Cognitive Skills or explicit knowledge required for the task that relates to the attainment of the task successfully . Successful and effective work performance is generally seen by many authors is to require a mix of both hard/cognitive skills and soft/behavioral skills .

Multitasking is the switching back and forth between ongoing tasks, known to psychologists as task switching; multitasking is often thought as performance of multiple tasks at one time although psychologically it actually takes attention from one to another and then back to the first with a fresh eye to an old task.An employee puts tasks in a sequential manner, switching to another task after completion of the one he/she is working on currently, while another employee constantly switches between tasks, and even works more tasks simultaneously; both these prototypical strategies can lie on a band, which can be the extent of multitasking behavior (Buser \& Peter, 2012; Mark, Gonzáles, \& Harris, 2005).Job performance has been defined, and widely accepted by scholars in organizational research, as behaviors within an individual's control that make a direct contribution to outcomes relevant to the organization(McCloy, Campbell\& Cudeck, 1994).

This research aims at finding the effect of organizational skills/Non Cognitive Skills and competencies/Cognitive Skills job performance while mediating the ability to multitask. which would help answer the questions that what are the components of Organizational Skills and Multitasking?, what is the impact of organizational skills and competencies towards multitasking? What is the relationship between Multitasking and Perceived Job Performance?, and, what is the mediation of Multitasking towards Job Performance?The purpose of this study is to identify whether multitasking is being affected by employee's organizational skills and competencies and further what impact multitasking creates on the employee's performance, which may help the decision makers identify workplace task assignment, determine goals and deadlines to achieve maximum performance, and, keep employees motivated and encouraged. The construct of organizational skills and competencies is operationalized through cognitive skills and behavioral attributes of the employees.

\section{LITERATURE REVIEW}

The nature of work at every level of organization has changed over the last decade or so and the environment has been constantly changing and evolving (Otto, Wahl, Lefort \& Frei, 2012), therefore doing a number of tasks at simultaneously is an widespread phenomena; the effect of this is yet to be determined and analyzed definitively with few researches pointing to the advantages and few otherwise (Buser \& Peter, 


\section{2).}

Today we live in a world where we look at humans as Human Capital rather than machines. The production of work product is a commodity that needs constant and continuous production. The different between performs is how well he or she can do something and how well can they do many things during the same time and this is dependent on what are the characteristics of attributes of the persons what of working or his personality . It has also been studies that employees have difficulty in performing task simultaneously, as there are generally negative social implications associated with multitasking .

According to Paridon and Kaufmann (2010), multitasking is not dependent on the age range of the subject but rather the individual capacity that person has to accomplish a certain set of tasks.Although multitasking is a general term but the effects and impact may depend on different factors ranging from the difference in the gender, experience and the fact that is the work load imposed or chosen, are the tasks of one job or different tasks of different jobs of a particular designation and the duration or time required for all (Buser\& Peter, 2012). There are four important predictor of multitasking in the work environment. Fists is arithmetic, that is about working with numbers, the second is memory search that is identifying and sequencing the letter in setting, third is auditory monitoring that is responding to high pitch and ignoring low pitch tones and last is visual monitoring that is identifying things being done correctly and $\mathrm{nr}$ reaching the red region .

Multitasking performance takes leads from two different conditions: whether multitasking is to be achieved within the same job or work or multitasking between different jobs; the task features look at characteristics of the task which incorporate physical, psychological, complexity or novelty attributes of the task . A few other task features are Structure of the task, timing, control and outcome of the task, the results may vary for different employees depending on their role, experience and hierarchal positions, therefore it is safe to infer that same multitasking situation may lead to different performance outcomes . In order to meet future needs of an organization, the employee competencies are developed and managed accordingly. For this purpose, individual competencies are defined for effective performance and then they are compared with the existing competencies . As perParidon \& Kaufmann (2010), multitasking has an impact on performance and the underlying mental mechanisms were in relation to performance values, psychological parameters and subjective strain. The steps highlighted by for identifying competencies are in seven different stages:examining competency modeling purpose, identifying job position and employees, defining the performance outcomes, identifying performance competencies, knowingperformance structures linked with individual competencies, knowing performance structures linked with organizational competencies, and identifying competencies is results validation.

The Core Skills and Competencies for multitasking include non-cognitive skills such as communicational skills, interpersonal skills and customer service as well as 
cognitive skills such as technological competence and analytical skills. The communication skills cover the written and oral forms of communication whereas the interpersonal skills cover the ability to have relationships at workplace and sharing of ideas as well as working cooperatively. Customer service at workplace points to the very fact the goals and objectives are kept in front and focus on service is kept foremost. A few other competencies and skills also include organizational understanding, workplace ethics, resource management and knowledge management (Chan, 2005). Researchers have also identified a few other competencies which are personal attributes of an employee, ability to self-motivate, skills for problem solving are a few top competencies and skills to be able to effectively multitask. .(See Figure 1 in Appendix)

The major competencies which are widely recognized are effective performance is categorized into communication skills, interpersonal skills, customer service and analytical skills (Chan, 2006).Furthermore, Chan (2010) identified two approaches to defining organizational competencies: personal or management competencies which are their knowledge skills and attitudes, and,organizational competencies which are those functions or practices which help any organization in converting the personal competency into organizational competency for instance extensive training methods or effective appraisal systems will result in better development of knowledge silks and abilities of any employee.

There are quite a few behavioral characteristics that differentiate one employee from another, known as employee competency or organizational skill . The employees would want to develop and add to the value they have by building on the competencies and the organization needs to utilize them in the best way possible. Competencies together define a manager's capacity to perform in different conditions and perform different tasks. For a superior performance, both these cognitive skills and behavioral attributes are required. Multitasking behavior may differ with Individual difference characteristics and cognitive and environmental factors. The individual difference characteristics are polychronicity which hypothesizes that value are related to actual behavior that means that prefers to multitask will multitask, impulsivity, which refers to tendency of switching from one task to another on impulse, cognitive interference, which explain how people think and engage in off-task cognitions, and, work and family demand that impact who will and who won't multitask (König \& Oberacher, 2010).

One may use different approaches for job performance design:in a blank slate approach, an organization may monitor the best performers to see what makes them the best in comparison to the average and below average workers, so the organization may define categories of there on. We can also look at another approach, where the organization looks for Role, a real Position, and additionally a person's strengths the position he/she currently plays and what are the weaknesses and develop competencies. 


\section{Conceptual Framework and Variables}

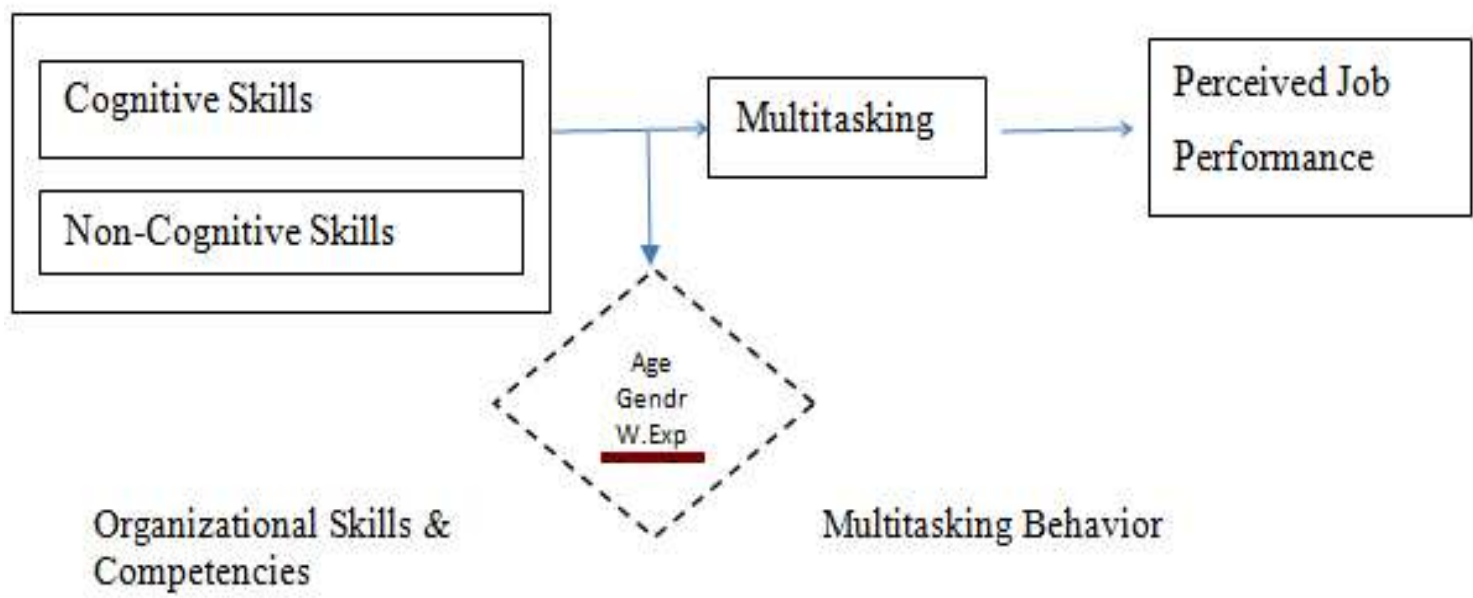

\section{RESEARCH METHODOLOGY}

The research follows post positivist philosophy and is deductive in nature as the model is developed through literature understanding and this study is hypothesizing the theory for the relative context. Mono method (survey) is used by the researcher by gathering quantitative, from large purposive sample through structured questionnaire using Likert scale. The research is generalized by applying statistical inferences and the results are explained by determining causal relationship between the constructs of this study .The target population for this research consists of the managers who are at the level of middle management with at least three years of working experience with minimum tertiary education level and has minimum five subordinates. Due to constraints of time and budget the managers are selected from banking sectors registered in Karachi.

H1: Cognitive skills has significant effect towards multitasking $\hat{E}$

$\mathrm{H} 2$ : Behavioral attributes has significant impact towards multitasking H3: Multitasking has significant affect towards Job Performance H4: Work experience and management position has an effect on multitasking. H5: There is a significant difference between male and female multitasking abilities

\section{ANALYSIS, FINDINGS AND DISCUSSION}

The research on organizational skills and competencies, which are further clarified as Cognitive and Non Cognitive skills and their effect on Multitasking capabilities for Job Performance tries to investigate the gaps of what triggers multitasking and if multitasking affects the overall Job Performance. The survey questionnaire was developed through adopted scales, responses of which were coded and analyzed using SPSS 21.0. The statistical tests such as: Cronbach Alpha was applied to assess the reliability, descriptive were calculated for assessing the contribution of each variable in survey, 
correlation was applied for relationships among variables, regression was applied to test the overall model fit and impacts.

Since the questionnaire was adopted from various studies, therefore validity of the tool was ensured through Face validity and Content Validity. For content validity the questionnaire was verified from two domain experts, whereby face validity was ensured by sending the questionnaires to the experienced people in Human Resource field.

The survey questionnaire was given to almost 136 participants, the returned usable questionnaires were 90 therefore the response rate is $66 \%$. The data was coded into nominal and scale variables to analyze the reliability that must be between $0-1$. For internal consistency the minimum Cronbach alpha must be $>=0.6$. Table 4.1 is signifying that the overall Cronbach alpha as well as for each construct is greater than 0.6 therefore the data is reliable enough for further statistical analysis.(See Table 1 in Appendix)

\subsection{Profiles of Participants}

Respondents profile was developed based on gender, marital status, age, work experience, and management position. Table 4.2 summarizes the profile of the respondents (See Table 2 in Appendix).

\subsection{Descriptive Analysis of Variables}

The constructs of this study is developed on 5 point likert scale with $1=$ strongly disagree and $5=$ strong agree. Since the constructs of this study had many elements in the questionnaire therefore overall mean was computed through arithmetic mean or average of all the scales within the construct. Table 4.3 represents mean and standard deviation of all the constructs. (See Table 3 in Appendix)

The mean value of each variable indicates the contribution of construct towards the study. Since all the variables mean $>3$ therefore the constructs are approximately contributing positively towards the model. Moreover, standard deviation is $<=0.5$ indicating that there is less variation is the opinion of the respondents.

All the variables agreeing with the framework with mean above 3 and low standard deviations that's shows not too much of a difference in results of participants of the research in terms of demographic variables.

\subsection{Association}

(See Table 4 in Appendix) The significant correlations among variables allow performing the regression analysis between independent variables towards intervening leading to the dependent variable of job performance. The association matric indicates significant positive correlations among the variables of the model. The independent variables such as cognitive skills and non-cognitive skills have positive significant relationship with the intervening variable of multitasking abilities. 


\subsection{Dependence Analysis}

For the purpose of regression analysis the framework of this research is divided into two models:

Model 1: Regression between Cognitive and Non-cognitive Skills toward Multitasking abilities

Model 2: Regression between Multitasking and Job Performance

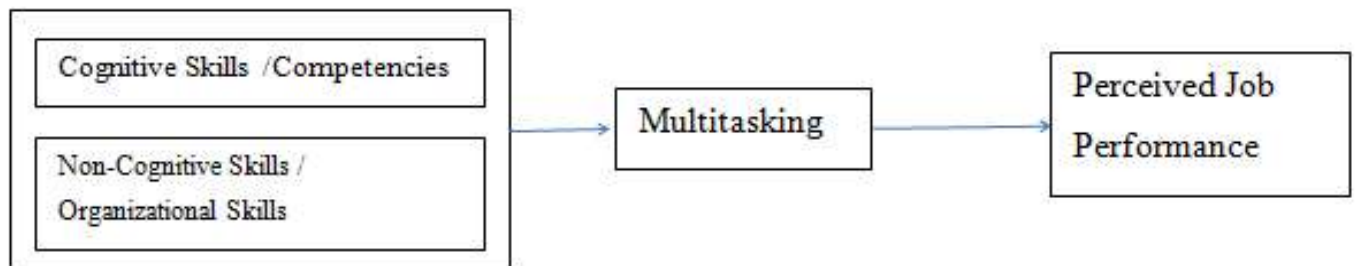

The Framework has been analyzed in two models. The first model describes the organizational skills and competencies towards multitasking and the second model looks at the effect of multitasking towards perceived job performance with multitasking as the intervening variable.

\section{Model 1:}

Table 4.5 depicts the regression analysis between independent variables cognitive and non-cognitive skills towards multitasking. (See Table 4 in Appendix)

\subsection{Dependent Variable: Multitasking}

Model 1 regression analysis shows the adjusted $\mathrm{R}$-square $=0.409$ at $\mathrm{F}=31.804$ and $\operatorname{sig}=.000$, therefore since $\mathrm{p}$-value $<0.05$ therefore we can conclude that $40.9 \%$ variance in multitasking is significantly explained by cognitive and non-cognitive skills of the employees. The unstandardized Beta coefficients of independent variables are also significant at 0.000 level, furthermore it indicate that cognitive skills is a better predictor of multitasking then non-cognitive skills. T-statistics $>2$ indicate that both the parameters have negligible chance of being zero. The results have led to the acceptance of the following hypothesis:

With reference to the literature review, the results provide confirmation to the researches which have a diverse opinion on the effects on Multitasking on Perceived Performance, which few researches showing positive effect of multitasking to Perceived Performance and few showing vice versa and. This Research in the particular area and environment also validates researches of similar idea to other populations that the Organizational Skills/Non Cognitive and Competencies/Cognitive Skills significantly effects and explains multitasking and multitasking behaviors with adjusted R square 
over 40.9 percent and collective sum Beta over 86 percent. The beta explains further that Non Cognitive Skills or organizational skills are better predictor for multitasking; however Hypothesis 1 and 2 are both accepted meaning Organizational Skills and Competencies both have significant effect towards multitasking.

H1: Cognitive skills has significant effect towards multitasking

Since p-value $<0.05$ therefore we can accept the alternate hypothesis and conclude that cognitive skills has significant positive impact towards multitasking. Therefore if cognitive skills increase by 1 ; multitasking will increase by $38.1 \%$.

H2: Behavioral attributes has significant impact towards multitasking

Since $p$-value $<0.05$ therefore we can accept the alternate hypothesis and conclude that non-cognitive skills or behavioral attributes have significant positive impact towards multitasking. Therefore if non-cognitive skills increase by 1; multitasking will increase by $48.4 \%$

\section{Model 2:}

(See Model 2 in Appendix)

\subsection{Dependent Variable: Job Performance}

Model 2 regression analysis shows that multitasking has positive impact towards the job performance. The overall model is fit with adjusted R-square indicating $14.6 \%$ variation in job performance explained by multitasking at 0.000 significance with Fvalue $=16.20$.

Furthermore, it leads to the acceptance of the following hypothesis:

H3: Multitasking has significant affect towards Job Performance

The coefficient of multitasking in model has $p$-value $<0.05$ therefore we can accept the alternate hypothesis and conclude that multitasking has positive significant effect towards job performance such that is multitasking increase by 1 job performance will increase by $39.4 \%$. Although both models show acceptability however the Model 1 shows strong relationship whereas Model 2 shows moderate.

Model 2 however has adjusted R square of only $14.6 \%$ showing that model only has moderate effect on Perceived Job Performance and Multitasking has only just over $39 \%$ percent effect in the overall model. This also shows that there are several more variables that have an effect on perceived Job Performance other than Multitasking as well, however we also can accept the Hypothesis 3 stating multitasking has a significant effect on Job Performance although it has to be understood also that it is not the only variables that contributes to Performance.

\subsection{Moderation of Demographic Variables}

The moderation of socio-demographic variables is assessed through Two Stage Least Square Method. This method considers categorical variables as predictors of the 
moderation on the relationship of independent and dependent variable. The researcher aims to assess if socio-demographic variable mediates the impact of organizational skills and competencies operationalized through cognitive and noncognitive skills towards multitasking abilities. Table 4.6 summarizes the effect of each moderating variable on the regression analysis. (See Table 6 in Appendix)

Therefore, the aforementioned table verifies the following hypothesis: H4: Work experience and management position moderates the regression between cognitive, non-cognitive and multitasking skills.

The demographic moderators when analyzed showed interesting results. Age and Gender had no significant effect on multitasking abilities however Work Experience and Management Position had significant ones . Work Experience showed positive effect showing more the experience, more the effect and chances of multitasking however Management Position showed negative effect in terms of the higher the management position, lower the multitasking behavior in participant. The literature also points to the higher level employees having long term and departmental outlook are not too involved in Multitasking however middle level managers are better Multitaskers as they keep on gathering more experience of the positions they work in therefore we can safely accept the hypothesis that managerial positions and work experience affects Multitasking abilities as also pointed out in the literature. (König \& Oberacher, 2010)

Categorical Variable Mean Comparison - Independent Sample t-test Independent sample t-test is performed to verify the following hypothesis:

H5: There is a significant difference between male and female multitasking abilities

(See Table 7 in Appendix)

\subsection{ANOVA}

One way ANOVA is applied to analyze the difference of multitasking among age groups, work experience categories and management positions held by the employees.

H6: Significant difference exist between age groups and multitasking abilities abilities

H7: Significant difference exists between work experience and multitasking

H8: Significant difference exists between Management position held by employees and multitasking abilities (See Table $7 \mathrm{~b}$ in Appendix)

\subsection{Mediation Testing}

To check the mediation of Multitasking between Organizational Skills and Competencies towards Job Performance.Sobel's Test has been used. In this test if Mediation is not there and p>0.05 than $\mathrm{HO}$ is accepted otherwise $\mathrm{Ha}$ is accepted if mediation is there. Since P Values are less than 0.05 , we conclude that multitaskinghas a mediating effect between organizational skills and competencies towards and job 
performance.

\section{CONCLUSIONS AND RECOMMENDATION}

The study conducted validates all hypotheses and sheds light on the effect of cognitive and non-cognitive skills on an employee's ability to multitask. The study conducted validates all hypotheses and sheds light on the effect of cognitive and noncognitive skills on an employee's ability to multitask. The Non Cognitive Skills however have a stronger effect on the multitasking behavior as it covers characteristics of person's relationships, relations, motivation, background as well as management positon and experience of the task and in the organization. The Cognitive skills or competencies and Behavioral attributes that is organizational skills almost cover the entire effect on the multitasking behavior however multitasking on the other hand doesn't cover the entire effect on the perceived performance of the employee.

The recommendations after this study are:

1. Organizations must develop the System and incentive by Focusing on Behavior and culture to multi task rather than focusing on cognitive skills whichare already inherent in the process of Hiring.

2. Multitasking is not the only determinant to Job Performance, actually it is only a portion and there are other variables too.

3. Higher management position employees multitask less and this can be a demotivation for the junior employees who can and do multitasking bets therefore Management needs to be an example in order to promotemultitasking

\section{REFERENCES}

Alfes, K., Truss, C., Soane, E., Rees, C., \& Gatenby, M. (2013). The Relationship between Line Manager Behavior, perceived HRM practices, and Individual Performance: Examining the Mediating Role of Engagement. 52(6), 839-859.

Asif Khan, M., Ur-Rehman, K., -Ur-Rehman, I., Safwan, N., \& Ahmad, A. (2011). Modeling link between internal service quality in human resources management and employee retention: A case of Pakistani privitazied \& public sector bank. African Journal of Business Management, 5, 949-959.

Baron, J., \& Norman, F. (2009). SATs Acheivement Tests, and High School Class Rank as predictors of College Performance. Educaion and Pshycology Measurment, 1047-1054.

Bell, C. S., Compeau, D. R., \& Olivera, F. (2005). Understanding the Social Implications of Technological Multitasking: A Conceptual Model. Association for Information Systems AIS Electronic Library (AISeL) (pp. 79-84). Bell et al. Understanding the Social Implications of Technological Multitasking. 
Burawat, P. (2013). The relationship among perceived employer branding, employee engagement, and discretionary effort in the petroleum industry.

Burchell, D. H. (2003). Business Graduate Competencies: Employers' Views on Importance and Performance. Aukland, New Zealand: AsiaPacific Journal of Cooperative Education .

Buser, T., \& Peter, N. (2012). Multitasking. Springer, 641-655.

Campion, M. A., Fink, A. A., Ruggeberg, B. J., Carr, L., Phillips, G. M., \& Odman, R. B. (2011). Doing competencies well: Best practices in competency modeling. Personnel Psychology, 64(1), 225-262.

Chen, L. C., \& Wallace, M. (2011). Multiskilling of frontline managers in the five star hotel industry in Taiwan. Research and Practice in Human Resource Management, 19(1), 25.

Chalofsky, N. (2010). Meaningful workplaces. San Francisco.

Chan, D. C. (2005). Core Competencies and Oerformance Management in Canadian Libraries. Emarald Insight, 144-153.

Chan, D. C. (2006). Core Competencies and Perfromance Management in Canadian Public Libraries. Emerald Insight, 144-153.

Chase, M. A., Lirgg, C. D., \& Feltz, D. L. (1997). Do Coaches' Efficacy Expectations for Their Teams Predict Team Performance? . The Sporr Psychologist, 823.

Corporate Leadership Council. (2014). Retrieved from https://clc.executiveboard.com/Members/Popup/Download.aspx?cid=101 196551

Covey, S. (n.d.). 7 Habits of Highly effective people.

Daniel Olympia, Susan Sheridan, William Jenson, and Debra Andrews, 1994 . (n.d.).

Daraei, M., \& Vahidi, T. (2014). Designing a Conceptual Model for analyzing the relation between strategic knowledge Management \& Talent Management Strategy in Profitability of the Southern Khorasan Electric Distribution Company (SKEDC). Global Journal of Management and Business.

Deal, K. H., \& Clements, J. A. (2006). Supervising students developmentally: evaluating a seminar for new field instructors. Journal of Social Work Education , 291299. 
Duru-Bellat, M., \& Tenret, E. (2012). Who's for Meritocracy? Individual and Contextual Variations in the Faith. Chicago Journal, 56(2), 223-247.

Ellis, K., \& Shockley-Zalabak, P. (2009.). Trust in top management and immediate supervisor: The relationship to satisfaction, perceived organizational effectiveness, and information receiving. 49(4), 382-398. Retrieved from http://www.tandfonline.com/loi/rcqu20

Ezaili Alias, N., Mohd Noo, N., \& Hassan, R. (2014). Examining the Mediating Effect of Employee Engagement on the Relationship between Talent Management Practices and Employee Retention in the Information and Technology (IT) Organizations in Malaysia. Journal of Human Resources Management and Labor Studies, 2(2), 227-242.

Faisal Ahammada, M., Yedidia Tarba, S., Liu, Y., \& W. Glaister, K. (2014). Knowledge transfer and cross-border acquisition performance: The impact of cultural distance \& employee retention. International Business Review.

F. Love, L., \& Sing, P. (2011). Workplace Branding: Laveraging Human Resources Management Practices for Competitive Advanta

Gibson, C. B. (2003). The Efficacy Advantage: Factors Related to the Formation of Group Eff icacy. Journal of Applied Social Psychology, 2153-2186.

Gillet, N., Gagné, M., Sauvagère, S., \& Fouquereau, E. (2012). The role of supervisor autonomy support, organizational support, and autonomous and controlled motivation in predicting employees' satisfaction and turnover intentions. European Journal of Work and Organizational, 22 (4), 450-460.

Gollan, P. J., Martin, G., \& Grigg, K. (2011). Is there a bigger and better future for Employer Branding? Facing up to innovation, corportae reputations and wicked problems in SHRM. The International Journal of Human Resource Management.

Griffin, M. A., Patterson, M. G., \& West, M. A. (2001). Job satisfaction and teamwork: the role of supervisor support. Journal of Organizational Behavior, 537550 .

Gulzar, S., \& Durrani, A. (2014). Impact of Succession Planning on Employe Engagement in Telecommunication Sector in Rawalpindi, Pakistan. European Journal of Business and Management, 6 (37).

Hambrik, D. Z., OSwald, F. L., Darowski, E. S., Rench, T. A., \& Brou, R. (2010). Predictors of Multitasking Performance in a Synthetic. APPLIED COGNITIVE PSYCHOLOGY , 1150-1167. 
Hewitt, A. (2013). Building the Right High Potential Pool, How Organizations Define, Assess, and Calibrate Their Critical Talent. Aon Hewitt.

Hodges, D., \& Burchel, N. (2003). Business Graduate Competencies: Employers' Views on Importance and. Faculty of Business, UNITEC Institute of Technology, Private Bag 92025, Auckland, New Zealand.

Humphreys, M. S., \& Revelle, W. (1984). Personality, motivation, and performance: A theory of the relationship between individual differences and information processing. Psychological Review, 153-184.

King, A. W., \& Zeithaml, C. P. (2010). Competencies and firm performance: Examining the causal ambiguity paradox . Strategic Management Journal, 75.

\section{Questionnaire Items}

SD: Strongly Disagree D: Disagree N: Neutral A: Agree SA: Strongly Agree Questions

Organizational Competencies

Cognitive

1.I would prefer complex to simple problems.

2.I like to have the responsibility of handling a situation that requires a lot of thinking.

3.Thinking is not my idea of fun

4.I would rather do something that requires little thought than something that is sure to challenge my thinking abilities

5.I try to anticipate and avoid situations where there is likely a chance I will have to think in depth about something

6.I find satisfaction in deliberating hard and for long hours

7.I only think as hard as I have to

8.I prefer to think about small, daily projects to long-term ones

9.I like tasks that require little thought once I've learned them

10.The idea of relying on thought to make my way to the top appeals to me 11.I really enjoy a task that involves coming up with new solutions to problems 12.Learning new ways to think doesn't excite me very much

13.I prefer my life to be filled with puzzles that I must solve

14.The notion of thinking abstractly is appealing to me

15.I would prefer a task that is intellectual, difficult, and important to one that is somewhat important but does not require much thought

16. I feel relief rather than satisfaction after completing a task that required a lot of mental effort

17. It's enough for me that something gets the job done; I don't care how or why it works

18. I usually end up deliberating about issues even when they do not affect me personally 
Non Cognitive Skills

Extraversion

19. I am a talkative person

20. I like to my opinions to myself and prefer to keep quiet

21. I am outgoing sociable and make friends easily

Workplace Attitude and Behaviors

22. I come up with new ideas that others have not thought

23. I keep working hard and rarely take break

24. I enjoy working in things that take a very long time to complete

25. People take advantage of me

26. People are mean and not nice to me

Decision Making

27. I think about how the things I do will affect my future

28. I think carefully before I make an important decision

29. I ask for help when I don't understand something

30. I think about how the things I do will affect others

Achievement Striving

31. I do more than is expected

32. I strive to do everything in the best way

33. I try to outdo others, to be best

Fixed Vs Growth

34. I cannot change much as a person.

35. I can behave in various ways but my character cannot really be changed.

36. As much as I hate to admit it, I cannot teach old dog new tricks. I cannot change their most basic properties.

37. I have a certain personality, and not much can be done to change that.

Multitasking

38. I prefer to work on several projects in a day, rather than completing one project and then switching to another.

39. I would like to work in a job where I was constantly shifting from one task to another, like a receptionist or an air traffic controller

40. I lose interest in what I am doing if I have to focus on the same task for long periods of time, without thinking about or doing something else

41. When doing a number of assignments, I like to switch back and forth between them rather than do one at a time.

42. I like to finish one task completely before focusing on anything else.

43. It makes me uncomfortable when I am not able to finish one task completely before focusing on another task.

44. I am much more engaged in what I am doing if I am able to switch between several different tasks.

45. I do not like having to shift my attention between multiple tasks. 
46. I would rather switch back and forth between several projects than concentrate my efforts on just one.

47. I would prefer to work in an environment where I can finish one task before starting the next.

48. I don't like when I have to stop in the middle of a task to work on something else.

49. When I have a task to complete, I like to break it up by switching to other tasks intermittently.

50. I have a "one-track" mind.

51. I prefer not to be interrupted when working on a task.

Job Performance

52. I adequately complete assigned duties

53. I fulfill all responsibilities specified in job description

54. I perform tasks that are expected from me

55. I meet formal requirements of the job

56. I engage in activities that will directly affect my performance evaluation

57. I neglect aspects of job I am obliged to perform

58. I help others who have heavy work load

59. I give advance notice whenever unable to work

60. I pass along timely information to co-workers.

61. I always try to mentor and help new employees

\section{Acknowledgement}

It is hereby acknowledged the contribution of middle managers of different national and multinational banks who have provided the data and have given their valuable opinion for this research study.

\section{Appendix}

Table.1: Reliability of Constructs

\begin{tabular}{|l|c|l|}
\hline Construct & Reliabil & Items \\
\hline Cognitive Skills & .622 & 18 \\
\hline Non-Cognitive Skills & .693 & 19 \\
\hline Multitasking & .837 & 14 \\
\hline Job Performance & .715 & 10 \\
\hline Overall & .803 & 61 \\
\hline
\end{tabular}


Figure.1: Oswald, Hambrick, Jones, \& Ghumman (2007)

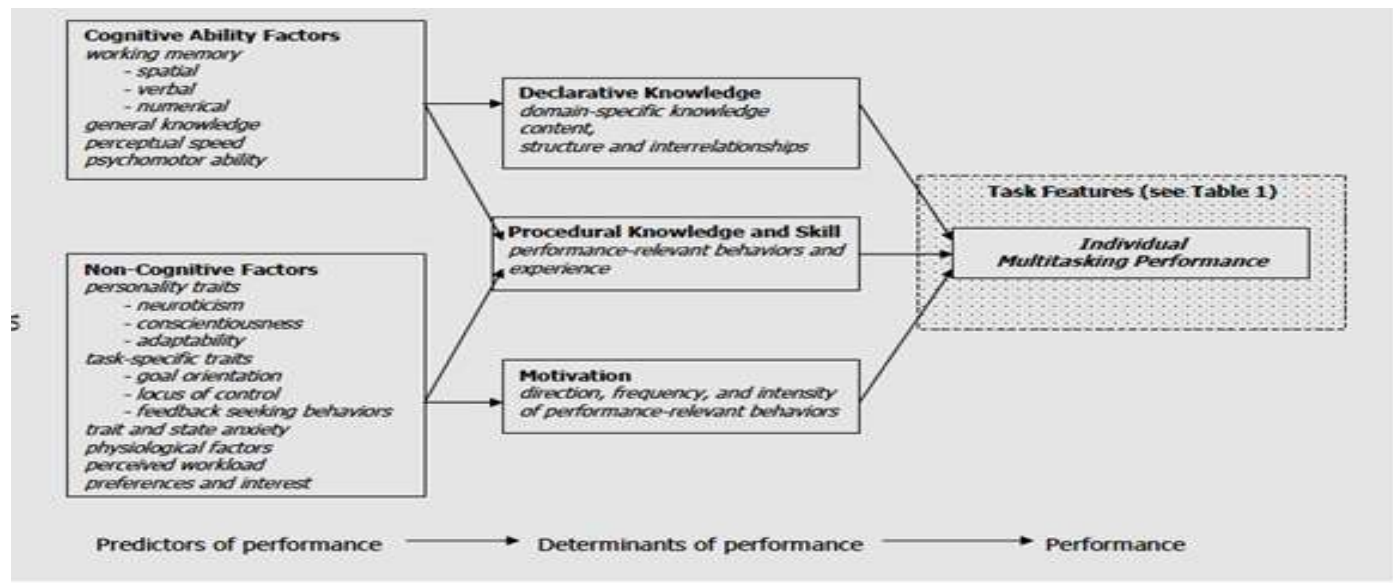

Table.2: Profile of Respondents

\begin{tabular}{|l|l|l|l|}
\hline Profile & Groups & Frequency & \%ages \\
\hline \multirow{3}{*}{ Gender } & Male & 64 & $71 \%$ \\
\cline { 2 - 4 } & Female & 26 & $29 \%$ \\
\hline \multirow{4}{*}{ Age } & $18-25$ & 17 & $18.9 \%$ \\
\cline { 2 - 4 } & $25-35$ & 41 & $45.6 \%$ \\
\cline { 2 - 4 } & $35-45$ & 20 & $22.2 \%$ \\
\cline { 2 - 4 } & $45+$ & 12 & $13.3 \%$ \\
\hline Marital Status & Single & 35 & $39 \%$ \\
\cline { 2 - 4 } & Mamied & 55 & $61 \%$ \\
\hline Work Experience & $1-3$ years & 32 & $35.6 \%$ \\
\cline { 2 - 4 } & $3-5$ years & 21 & $23.3 \%$ \\
\cline { 2 - 4 } & $5-7$ years & 37 & $41.1 \%$ \\
\hline Management Position & Junior & 33 & $36.7 \%$ \\
\cline { 2 - 4 } & Middle & 41 & $45.6 \%$ \\
\cline { 2 - 4 } & Senior & 16 & $17.8 \%$ \\
\hline
\end{tabular}

Table.3: Descriptive Analysis

\begin{tabular}{|l|c|c|c|c|c|}
\hline & N & $\begin{array}{c}\text { Minim } \\
\text { um }\end{array}$ & $\mathbf{m}^{\text {Maximu }}$ & $\mathbf{n}^{\text {Mea }}$ & SDeviation \\
\hline Cognitive & 90 & 1.61 & 4.17 & $19^{3.05}$ & .44993 \\
\hline Non-cognitive & 90 & 2.37 & 4.11 & $0^{3.45}$ & .33963 \\
\hline Multitasking & 90 & 1.14 & 4.36 & $79^{3.10}$ & .59965 \\
\hline $\begin{array}{l}\text { Job } \\
\text { Performance }\end{array}$ & 90 & 3.30 & 4.70 & $0^{3.79}$ & .27439 \\
\hline
\end{tabular}


Table.4: Correlation among variables

\begin{tabular}{|c|c|c|}
\hline Variable & Multitasking & Significance \\
\hline Cognitive Skills & $.438^{* *}$ & .000 \\
\hline $\begin{array}{c}\text { Non-Cognitive } \\
\text { Skills }\end{array}$ & $.518^{* *}$ & .000 \\
\hline Job Performance & $.394^{* *}$ & .000 \\
\hline \multicolumn{2}{|c|}{$*$ Correlation is significant at the 0.01 level (2-tailed). } \\
\hline
\end{tabular}

Table.5: Regression Analysis of independent variables towards Multitasking

\begin{tabular}{|c|c|c|c|c|}
\hline R-Square & \multicolumn{2}{|l|}{.422} & & \\
\hline Adjusted R-Square & \multicolumn{2}{|l|}{.409} & & \\
\hline F-Value & \multicolumn{2}{|l|}{31.804} & & \\
\hline Significance & \multicolumn{2}{|l|}{.000} & & \\
\hline \multicolumn{5}{|l|}{ Coefficient } \\
\hline & Un SD Beta & Beta & t-statistic & Sig \\
\hline Cognitive Skills & .508 & .381 & 4.641 & .000 \\
\hline Non-Cognitive Skills & .279 & .484 & 5.896 & .000 \\
\hline
\end{tabular}

Model 2

\begin{tabular}{|l|l|l|l|l|}
\hline \multicolumn{4}{|l|}{ Regression Analysis of Multitasking towards Job Performance } \\
\hline R-Square & .155 & \multicolumn{2}{l|}{} \\
\hline Adjusted R-Square & .146 & & \\
\hline F-Value & 16.2 & & \\
\hline Significance & .000 & & \\
\hline Coefficient & Un SD Beta & Beta & t-statistic & Sig \\
\hline & .257 & .394 & 4.025 & .000 \\
\hline Multitasking &
\end{tabular}


Table.6: Moderating variables on regression of model 1

\begin{tabular}{|c|c|c|c|c|c|}
\hline $\begin{array}{l}\text { Categorical } \\
\text { Variable }\end{array}$ & $\begin{array}{l}\text { Adjuste } \\
\mathrm{d} \\
\mathrm{R}- \\
\text { square }\end{array}$ & Beta & $\begin{array}{c}\mathrm{t}- \\
\text { statistic }\end{array}$ & $\begin{array}{c}\mathrm{p}- \\
\text { value }\end{array}$ & Analysis \\
\hline Age & .020 & $8^{2.48}$ & $1^{1.67}$ & $8^{.09}$ & $\begin{array}{l}\text { Since p-value }>0.05 \text { therefore Age } \\
\text { has no moderation effect }\end{array}$ \\
\hline Gender & -.011 & $68^{56.3}$ & .133 & $5^{.89}$ & $\begin{array}{c}\text { Since p-value }>0.05 \text { therefore } \\
\text { Gender has no moderation effect }\end{array}$ \\
\hline $\begin{array}{c}\text { Work } \\
\text { Experience }\end{array}$ & .034 & $3^{1.11}$ & $2^{2.04}$ & $4^{.04}$ & $\begin{array}{l}\text { Since p-value }<0.05 \text { therefore more } \\
\text { work experience will positively } \\
\text { moderate the regression by } 3.4 \% \text {. }\end{array}$ \\
\hline $\begin{array}{l}\text { Management } \\
\text { Position }\end{array}$ & .036 & 2.388 & 2.069 & $1^{.04}$ & $\begin{array}{l}\text { Since p-value } 0.05 \text { therefore } \\
\text { management position negatively } \\
\text { moderates the regression by } 3.6 \% \text {. i.e. } \\
\text { lower position has more impact } \\
\text { towards the relationship }\end{array}$ \\
\hline
\end{tabular}

Table. 7

\begin{tabular}{|c|c|c|l|}
\hline & $\begin{array}{c}\text { F- } \\
\text { Value }\end{array}$ & Sig & Description \\
\hline Multitasking & 6.219 & .015 & $\begin{array}{c}\text { Since p-value }<0.05 \text { therefore there is a significant } \\
\text { difference in male and female multitasking abilities }\end{array}$ \\
\hline
\end{tabular}

Table.7 (b): The ANOVA results for the three mentioned hypothesis

\begin{tabular}{|c|c|c|c|}
\hline Category & F-value & Sig & Description \\
\hline $\begin{array}{c}\text { Multitasking and } \\
\text { age groups }\end{array}$ & 1.679 & .149 & $\begin{array}{c}\text { Since all p-values }>0.05 \text { therefore none of } \\
\text { the categories have significant difference } \\
\text { among groups and the multitasking abilities }\end{array}$ \\
$\begin{array}{c}\text { Multitasking and } \\
\text { work experience }\end{array}$ & .568 & .569 & .293 \\
$\begin{array}{c}\text { Multitasking and } \\
\text { Management Position }\end{array}$ & .1244 & \multicolumn{1}{|c|}{} \\
\hline
\end{tabular}

